astrocytoma was diagnosed in 3 cases, 2 received treatment with mTOR inhibitor, and one child underwent VP shunt due to enlarging SEGA causing obstructive hydrocephalus. Six $(55 \%)$ of the children with TSC suffered from epilepsy and psychomotoric development delay.

Although CRs are benign from the cardiovascular standpoint, and have a natural history of spontaneous regression, their close association with TSC prompt for early prenatal diagnosis and family counselling regarding the dismal longterm prognosis. Recent literature suggests that early therapy with mTOR inhibitors may prevent the development of TS manifestations.

\section{THE ANTIARRHYTHMIC EFFICACY OF H1 - HISTAMINE RECEPTOR BLOCKER QUIFENADINE IN CHILDREN WITH FREQUENT EXTRASYSTOLES}

Larisa Balykova*, Makarov Leonid, Soldatov Oleg, Soldatov Yuri, Shekina Nataliya. National Research Ogarev Mordovia state University

\subsection{6/archdischild-2021-europaediatrics. 181}

Goal to determine safety and efficacy of quifenadine versus amiodarone in children with premature beats (PB).

Methods 84 patients (mean age $10.4 \pm 3.8$ yrs) with frequent (>10000 during

$24 \mathrm{~h})$ ventricular $(\mathrm{n}=45)$ and supraventricular $(\mathrm{n}=39)$ PB were randomized $1: 1$ to quifenadine $(1-3 \mathrm{mg} / \mathrm{kg} /$ day, $\mathrm{n}=54)$ or amiodarone $(8-10 \mathrm{mg} / \mathrm{kg} / \mathrm{day}, \mathrm{n}=30)$ arms. The therapeutic efficacy was evaluated by 24 -hour Holter monitoring at

2-4 and 9-12 weeks of treatment.

Results Complete antiarrythmic effect ( $\mathrm{PB}<50 \%$ from baseline) has been achieved in 23/54 (43\%) of quifenadine-treated patients, which was less than in amiodarone groupe (24/30, $80 \%, \mathrm{p}=0.02)$. Quifenadine was mostly beneficial in children with supraventricular PB and/or bradycardia. Quifenadine therapy led to moderate QTc interval prolongation without exceeding of clinically meaningful values. The side effect incidence in quifenadine group (drowsiness and headache) was significantly lower (2\%) than in amiodarone group (40\%, $\mathrm{p}<0.05)$. In case of lack of quifenadine and amiodarone alone effect, combination therapy was used (quifenadine $1-2 \mathrm{mg} / \mathrm{kg}$ / day and amiodarone 4-6 mg/ $\mathrm{kg} /$ day). The combination therapy showed complete antiarrhythmic effect in 10/12 (83\%) of patient without significant QT prolongation or sinus node depression (probably due to quifenadine antiholinergic properties). The only side effect was thyroid dysfunction $(8,3 \%)$ in this group.

Conclusion The obtained data have shown quifenadine antiarrhythmic activity in children with premature beats. Quifenadine with amiodarone combination led to decrease antiarrhythmic side effects incidence while maintaining it therapeutic efficacy.

\section{TWENTY YEARS OF HYPOPLASTIC LEFT HEART SYNDROME IN CROATIA}

Viktorija Ana Buljević*, Andrea Dasović Buljević, Dorotea Bartoniček, Dalibor Šarić, Daniel Dilber. University Hospital Centre Zagreb

10.1136/archdischild-2021-europaediatrics.182
Hypoplastic left heart syndrome (HLHS) is rare congenital heart defect in which the left side of the heart is severely underdeveloped. It has been a lethal congenital heart anomaly until the last four decades until three palliative surgeries were established (operation by Norwood, Glenn and Fontan). The aim of this study was to evaluate the outcomes of treating patients with HLHS.

The main methods were statistical, and the clinical characteristics were retrospectively reviewed.

We included 132 patients in 20-year period who have been treated at University Hospital Centre Zagreb, operated in our and in foreign centers.

We followed them before, in the meantime and after final operation. Of all patients, 69 survived and 63 died. The highest mortality was in period between operation by Norwood and Glenn in early infancy and accounts for almost $48 \%$ all lethal outcomes.

The most common anatomic variant is the mitral atresia and aortic atresia

(MA-AA) subtype and the rarest is mitral stenosis and aortic atresia (MS-AA) subtype.

Apart of a three - staged operation procedures, 53 patients required one or more interventions involving implantation of the stent into the pulmonary branches, isthmus the aorta, the Sano or mBT junction, and the dilatation of the same, then coiling of the arteriovenous malformations, electrostimulator implantation and the closure of fenestra. The most common interventions are stent implantation into the pulmonary branches and dilatation of the aortic recoarctation and stenosis of the pulmonary branch stent. In twelve patients, fenestra was closed with an Amplatzer occluder.

The mean follow-up age operation by Fontan (TCPC) is 7.64 years $(1.1-$

16.5 years). Two patients were transferred to the GUCH population.

This retrospective study included 132 patients with hypoplastic left heart syndrome in twenty-year period who have been treated at University Hospital Centre Zagreb. The overall survival of all patients is $52.2 \%$. The highest mortality was in period between operation by Norwood and Glenn in early infancy. The most common interventions are stent implantation into the pulmonary branches and dilatation of recoarctation of the aorta. Mean follow-up age operation by Fontan (TCPC) is 7.64 years.

\section{CHILDREN WITH BRAIN DEATH - FINDINGS ON ECHOCARDIOGRAPHY}

Vesna Herceg-Čavrak*, Sanja Pek, Ivančica Škarić, Višnja Tokić Pivac. Children's Hospital Zagreb

\subsection{6/archdischild-2021-europaediatrics. 183}

Brain death is frequently associated with systolic dysfunction. The actual mechanisms are not yet completely understood.

The goal of this study is to assess echocardiography findings among organ donors in our institution.

Methods we conducted a retrospective study for the period of 17 years (October 2001- December 2018). A total of 20 patients under 18 years with declared brain death were identified. The mean age was 8.8 years and 70\% (14 patients) were male. One patient had a history of cardiac disease - ventricular septal defect- and his heart was not accepted for donation. 